\title{
Evaluasi Pembelajaran Pendidikan Jasmani Berbasis Kurikulum 2013 di Sekolah Menengah Atas
}

\section{Evaluation Of 2013 Curriculum Based Physical Education Learning In High Schools}

\author{
Amrizal Fadila1 ${ }^{1}$, Didik Rilastiyo Budi² ${ }^{2}$ Arfin Deri Listiandi ${ }^{3}$, Ngadiman $^{4}$, Rifqi Festiawan ${ }^{5}$ \\ 1,2,3,4,5 Jurusan Pendidikan Jasmani, Fakultas IImu-IImu Kesehatan, Universitas Jenderal \\ Soedirman, Indonesia \\ email: fadilaamrizal@gmail.com¹, didik.rilastiyo.budi@unsoed.ac.id² , \\ arfinderilistiandi@unsoed.ac.id ${ }^{3}$ \\ do \\ https://doi.org/10.20884/1.paju.2021.3.1.4350
}

\begin{abstract}
Abstrak
Kurikulum adalah program yang dijadikan pedoman untuk pelaksanaan pembelajaran yang berisi materi pelajaran agar tujuan pendidikan dapat tercapai. Kurikulum yang sedang diterapkan di Indonesia adalah Kuriukulum 2013. Mata pelajaran yang ada di dalam Kurikulum 2013 adalah Pendidikan Jasmani Olahraga dan Kesehatan. Masalah yang timbul adalah guru belum menerapkan pembelajaran yang memacu keterlibatan aktif siswa, waktu pembelajaran tidak sesuai, sistem penilaian yang diterapkan belum sesuai standar Kurikulum 2013. Penelitian ini bertujuan untuk mengetahui pelaksanaan pembelajaran PJOK Kurikulum 2013 di Kabupaten Banyumas Penelitian ini merupakan penelitian deskriptif kuantitatif dengan pendekatan survey. Sampel pada penelitian ini yaitu 26 guru dan 828 siswa SMA Sederajat. Teknik analisis data menggunakan statistik deskriptif. Hasil penelitian menunjukan bahwa hasil pelaksanaan pembelajaran PJOK pada aspek guru sebesar $85 \%$, aspek siswa $82,8 \%$, aspek pelaksanaan kompetensi inti $87,5 \%$, aspek pelaksanaan proses pembelajaran $86,1 \%$, aspek pelaksanaan penilaian $80,3 \%$, aspek kegiatan pendahuluan $87,6 \%$, aspek kegiatan inti $80,6 \%$, dan aspek kegiatan penutup 76,6\% .Kesimpulan berdasarkan analisis data menunjukkan pelaksanaan pembelajaran PJOK Kurikulum 2013 di Kabupaten Banyumas masuk kategori baik. penelitian selanjutnya perlu mengidentifikasi pelaksanaan pembelajaran penjas di jenjang Pendidikan yang berbeda, atau membandingkan metode evaluasi yang digunakan.
\end{abstract}

Kata Kunci : Evaluasi, Kurikulum 2013, Pendidikan Jasmani, Sekolah Menegah Atas

\begin{abstract}
The curriculum is a program that is used as a guide for the implementation of learning that contains subject matter so that educational goals can be achieved. The curriculum that is being implemented in Indonesia is the 2013 Curriculum. The subjects in the 2013 Curriculum are Physical Education, Sports and Health. The problem that arises is that the teacher has not implemented learning that encourages active student involvement, the learning time is not appropriate, the
\end{abstract}

Alamat Koresponden: Jurusan Pendidikan Jasmani, Fakultas IImu-IImu Kesehatan, Universitas Jenderal Soedirman,

Email: fadilaamrizal@gmail.com

(c) (i) (2)

Jurnal Physical Activity Journal (PAJU) is licensed under a Creative Commons Attribution-

ShareAlike 4.0 International License. 
assessment system applied is not in accordance with the 2013 Curriculum standards. This study aims to determine the implementation of the 2013 Curriculum PJOK learning in Banyumas Regency. surveys. The sample in this study were 26 teachers and 828 high school students equivalent. The data analysis technique used descriptive statistics. The results showed that the results of the implementation of PJOK learning in the teacher aspect were $85 \%$, student aspects $82.8 \%$, core competence implementation aspects $87.5 \%$, learning process implementation aspects $86.1 \%$, assessment implementation aspects $80.3 \%$, activity aspects preliminary activities $87.6 \%$, aspects of core activities $80.6 \%$, and aspects of closing activities $76.6 \%$. The conclusion based on data analysis shows that the implementation of the 2013 Curriculum PJOK learning in Banyumas Regency is in the good category. Further research needs to identify the implementation of physical education learning at different levels of education, or compare the evaluation methods used.

Keywords: Evaluation, 2013 Curriculum, Physical Education, Senior High School

\section{PENDAHULUAN}

Tahun 2020 ini seluruh sekolah di Indonesia sudah menerapkan Kurikulum 2013. Kurikulum 2013 adalah kurikulum berbasis karakter dan kompetensi (Mulyasa, 2017; Pangaribuan \& Aufan, 2020). Kurikulum 2013 merupakan pengembangan dari kurikulum sebelumnya yaitu Kurikulum Tingkat Satuan Pendidikan (KTSP) 2006. Karaktertik yang berbeda pada kurikulum sebelumnya dimiliki oleh Kurikulum 2013. Karakteristik Kurikulum 2013 terlihat pada standar isi dan standar prosesnya. Standar isi ialah kriteria mengenai ruang lingkup materi dan jenis kompetensi yang ingin dicapai. Standar proses ialah kriteria mengenai pelaksanaan pembelajaran (Kemendikbud, 2013).

Kegiatan Pembelajaran merupakan salah satu proses pembentukan kepribadian serta watak peserta didik melalui proses yang disebut belajar. Secara sengaja pembelajaran dilaksanakan untuk mengubah, mendidik, dan membimbing peserta didik menuju ke arah kedewasaan (Budi \& Listiandi, 2021; Dewi \& Sepriadi, 2021; Kirom, 2017). Pelaksanaan pembelajaran di sekolah dilakukan sesuai karakteristik Kurikulum 2013. Pembelajaran dibagi meliputi kegiatan pendahuluan, inti dan penutup. Kegiatan pendahuluan dilakukan pada awal pembelajaran dengan tujuan agar peserta didik siap untuk menerima pembelajaran. Kegiatan inti pada pembelajaran menggunakan model, metode, media, dan sumber pembelajaran yang disesuaikan dengan karakteristik peserta didik dan mata pelajaran (Karisman, 2020; Kemendikbud, 2013; Rojali et al., 2021). Sedangkan kegiatan penutup pada pembelajaran dilakukan untuk mengevaluasi kegiatan yang dilakukan. 
Amrizal Fadila, Didik Rilastiyo Budi, Arfin Deri Listiandi, Ngadiman \& Rifqi Festiawan | Evaluasi Pembelajaran Pendidikan Jasmani Berbasis Kurikulum 2013 di Sekolah Menengah Atas

Pendidikan Jasmani Olahraga dan Kesehatan (PJOK) merupakan salah satu diantara mata pelajaran lain yang ada pada Kurikulum 2013. Pendidikan Jasmani Olahraga dan Kesehatan (PJOK) pada hakekatnya merupakan proses pendidikan yang memberikan perhatian melalui aktivitas fisik atau pengembangan jasmani manusia (Agustan et al., 2020; Budi et al., 2019; Nur et al., 2020; Rokim \& Nurhayati, 2016). Berdasar pengertian tersebut PJOK mengimplementasikan kurikulum 2013 dalam bentuk aktivitas fisik.

Hasil penelitian lain menunjukan bahwa penerapan Kurikulum 2013 pada mata pelajaran PJOK adalah cukup baik namun masih banyak kekurangan. Masalah yang muncul pada pembelajaran PJOK yaitu guru masih belum paham dalam pelaksanaan Kurikulum 2013 dan kesulitan menerapkan pendekatan ilmiah dalam kegiatan belajar mengajar (Kusuma, 2015). Pembelajaran PJOK yang dilakukan di Nganjuk terdapat masalah berupa penyampaian materi yang tidak sesuai kaidah Kurikulum 2013 karena ada perbedaan dengan kurikulum sebelumnya (Rokim \& Nurhayati, 2016).

Permasalahan penerapan Kurikulum 2013 juga terjadi di Kota Purwokerto. Permasalahan tersebut di dapat dari hasil observasi pembelajaran yang dilakukan peneliti dengan dua guru PJOK dan wawancara peneliti dengan seorang guru PJOK di salah satu SMK Negeri Purwokerto. Observasi dan wawancara dilakukan oleh peneliti pada bulan Agustus-September 2019. Hasil yang didapat diantaranya beberapa guru masih menerapkan metode pembelajaran di KTSP, belum menerapkan pembelajaran yang memacu keterlibatan aktif peserta didik, waktu pembelajaran tidak sesuai, sistem penilaian yang diterapkan tidak sesuai standar penilaian Kurikulum 2013, masih ada guru yang tidak menyusun Rencana Pelaksanaan Pembelajaran (RPP).

Berdasarkan permasalahan di atas perlu ditindaklanjuti dengan sebuah penelitian sebab posisi kurikulum ialah sebagai alat pendidikan untuk mewujudkan tujuan pendidikan nasional yang perlu dilaksanakan sesuai kaidah dan peraturan pemerintah yang berlaku. Apabila pelaksanaan tidak sesuai maka tujuan pendidikan tidak akan tercapai. Penelitian ini nantinya mengetahui pelaksanaan pembelajaran PJOK yang dilakukan oleh guru dan siswa SMA/SMK/MA Negeri di Kabupaten Banyumas. Penelitian ini juga didukung dengan belum adanya penelitian sejenis di Kabupaten Banyumas. Tujuan dari penelitian ini yaitu untuk mengetahui efektivitas pembelajran penjas dengan kurikulum 2013 di Sekolah Menengah Atas di Kabupaten Bnayumas. 


\section{METODE}

Penelitian ini ialah penelitian deskriptif kuantitatif. Penelitian deskriptif merupakan penelitian yang bertujuan memberikan deskripsi dengan maksud menjawab pertanyaan atau pernyataan penelitian dengan sebenar-benarnya atau apa adanya (Sugiyono, 2016). Jumlah sampel penelitian ini adalah 26 orang guru PJOK dan 828 siswa kelas XI dan XII SMA Sederajat di Kabupaten Banyumas. Lokasi penelitian dilakukan di 17 SMA/SMK/MA Negeri.

Instrumen yang digunakan adalah kuesioner untuk mengukur pelaksanaan pembelajaran PJOK Kurikulum 2013 pada sapek siswa, guru, pelaksanaan kompetensi inti, proses pembelajaran, teknik penilaian, kegiatan pendahuluan, kegiatan inti, dan kegiatan penutup. Analisis data menggunakan statistik deskriptif. Instrumen penelitian menggunakan skala Likert. Pengolahan data menggunakan rumus :

$$
\frac{\text { Jumlah skor yang diperoleh }}{\text { Skor maksimal }} \times 100 \%
$$

Kemudian untuk menghitung persentase rata - rata pada tiap aspek pelaksanaan pembelajaran PJOK digunakan rumus yaitu :

$$
\frac{\text { Nilai Mean }}{\text { Skor maksimal tiap aspek yang dinilai }} \times 100 \%
$$

Setelah hasil persentase di dapat, kemudian dikategorikan berdasarkan kriteria pada Tabel 1. di bawah ini (Khudhori, 2015)

Tabel 1. Kriteria Pelaksanaan

\begin{tabular}{lll}
\hline No. & Presentase & Kategori \\
\hline 1. & $90 \%-100 \%$ & Baik Sekali \\
\hline 2. & $80 \%-89 \%$ & Baik \\
\hline 3. & $70 \%-79 \%$ & Cukup Baik \\
\hline 4. & $60 \%-69 \%$ & Kurang Baik \\
\hline 5. & $<60 \%$ & Tidak Baik \\
\hline
\end{tabular}

HASIL

Data penelitian diperoleh dengan cara memberikan angket kepada sampel penelitian. Hasil penelitian yang diperoleh berdasarkan angket dapat dilihat pada gambar 1 di bawah ini : 
Amrizal Fadila, Didik Rilastiyo Budi, Arfin Deri Listiandi, Ngadiman \& Rifqi Festiawan | Evaluasi Pembelajaran Pendidikan Jasmani Berbasis Kurikulum 2013 di Sekolah Menengah Atas

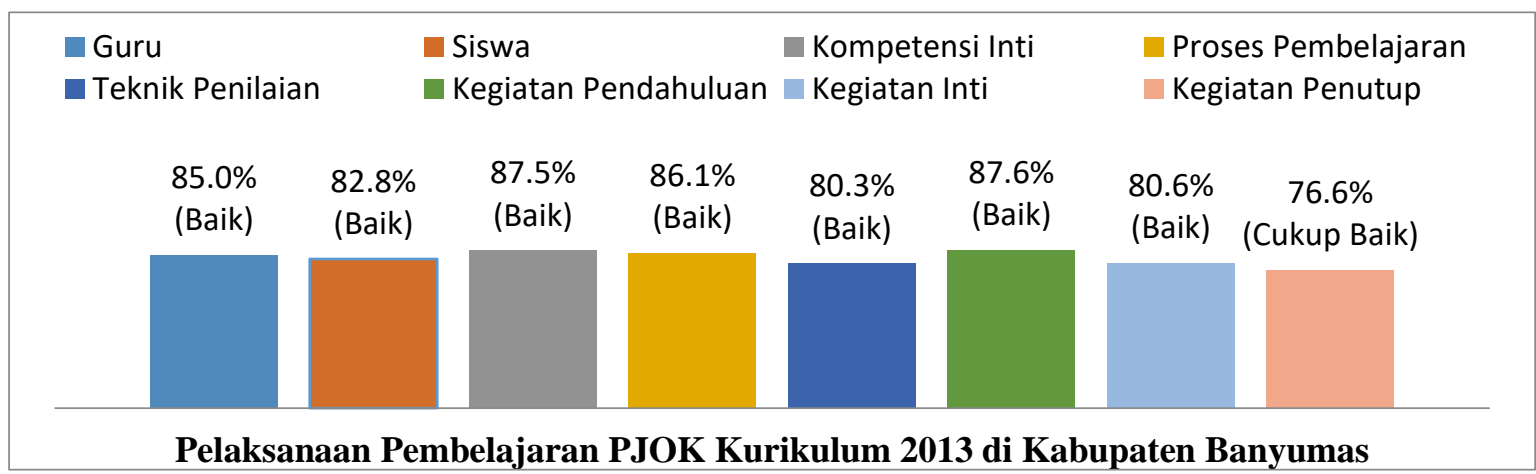

Gambar 1. Pelaksanaan Pembelajaran PJOK Kurikulum 2013

Berdasarkan gambar diatas diperoleh hasil pelaksanaan pembelajaran PJOK Kurikulum 2013 di Kabupaten Banyumas pada aspek guru masuk kategori Baik dengan persentase $85 \%$, aspek siswa masuk kategori Baik dengan persentase $82,8 \%$, aspek pelaksanaan kompetensi inti masuk kategori Baik dengan persentase $87,5 \%$ aspek pelaksanaan proses pembelajaran masuk kategori Baik dengan persentase $86,1 \%$, aspek pelaksanaan teknik penilaian masuk kategori Baik dengan persentase $80,3 \%$, aspek kegiatan pendahuluan masuk kategori Baik dengan persentase $87,6 \%$, aspek kegiatan inti masuk kategori Baik dengan persentase 80,6\%, dan aspek kegiatan penutup masuk kategori Cukup Baik dengan persentase 76,6\%.

\section{PEMBAHASAN}

Kurikulum 2013 merupakan kurikulum berbasis karakter dan kompetensi yang dirumuskan berdasar standar kompetensi lulusan. Karakteristik Kurikulum 2013 telihat pada standar isi dan standar proses. Standar isi adalah kriteria mengenai ruang lingkup materi dan jenis kompetensi. Standar proses ialah kriteria mengenai pelaksanaan pembelajaran (Kemendikbud, 2013). Pendidikan Jasmani Olahraga dan Kesehatan (PJOK) merupakan salah satu diantara mata pelajaran lain yang ada pada Kurikulum 2013. Pelaksanaan pembelajaran PJOK dimulai dari perencanaan pembelajaran, proses pembelajaran, dan proses penilaian. Dalam proses pembelajaran terdapat kegiatan pendahuluan, inti dan penutup.

Penelitian ini menilai pembelajaran PJOK Kurikulum 2013 pada aspek guru, siswa, pelaksanaan kompetensi inti, pelaksanaan proses pembelajaran, teknik penilaian, kegiatan pendahuluan, kegiatan inti, dan kegiatan penutup. Penelitian berpedoman pada pelaksanaan Standar Proses Kurikulum 2013 yang diubah dalam bentuk kuesioner 
penelitian. Tujuan penelitian ini untuk mengetahui sejauhmana pelaksanaan pembelajaran PJOK pada Kurikulum 2013 di Kabupaten Banyumas.

Penelitian ini menggunakan guru PJOK dan siswa SMA/SMK/MA Negeri di Kabupaten Banyumas. Jumlah sampel adalah 26 guru PJOK dan 828 siswa kelas XI. Hasil penelitian yang dilakukan menyatakan pelaksanaan pembelajaran PJOK Kurikulum 2013 di Kabupaten Banyumas memiliki rata - rata 83,3\% atau masuk kategori Baik dengan rincian pelaksanaan pada aspek guru PJOK sebesar $85 \%$, aspek siswa sebesar $82,8 \%$, aspek pelaksanaan kompetensi inti sebesar $87,5 \%$, aspek pelaksanaan proses pembelajaran sebesar $86,1 \%$, aspek pelaksanaan teknik penilaian sebesar $80,3 \%$, aspek kegiatan pendahuluan sebesar $87,6 \%$, aspek kegiatan inti sebesar $80,6 \%$ dan aspek kegiatan penutup sebesar $76,6 \%$.

Hasil penelitian ini menunjukkan adanya beberapa peningkatan pelaksanaan pembelajaran PJOK dibandingkan penelitian sebelumnya. Penelitian Khudhori (2015) di Kabupaten Jombang menghasilkan pelaksanaan pembelajaran pada aspek guru mempunyai nilai persentase $80,86 \%$ sedangkan pada penelitian ini pelaksanaan pembelajaran pada aspek guru mempunyai nilai persentase $85 \%$. Kenaikan persentase tersebut menunjukkan adanya peningkatan pemahaman guru terkait pembelajaran PJOK Kurikulum 2013. Pada aspek siswa penelitian Khudhori (2015) mempunyai nilai persentase $59,25 \%$ sedangkan penelitian ini menghasilkan nilai persentase sebesar $82,8 \%$. Dalam jarak waktu kurang lebih 5 tahun pelaksanaan pembelajaran PJOK Kurikulum 2013 mengalami peningkatan yang sangat baik pada aspek siswa dengan menilai pembelajaran yang dilakukan oleh guru PJOK. Penelitian lain dari Rokim \& Nurhayati (2016) menyatakan pelaksanaan pembelajaran PJOK Kurikulum 2013 di Kabupaten Nganjuk yang dilakukan oleh guru PJOK mendapatkan nilai 75,63\%, berdasarkan hasil tersebut penelitian ini juga membuktikan adanya peningkatan pelaksanaan pembelajaran pada aspek guru PJOK.

Melihat penelitian sebelumnya yang telah dilakukan, kelebihan penelitian ini membahas pelaksanaan pembelajaran PJOK Kurikulum 2013 lebih dalam dan lebih terperinci sampai kepada subvariabel. Hal tersebut memberikan keuntungan sendiri bagi penyelenggaraan pendidikan di Kabupaten Banyumas untuk bahan evaluasi dalam pelaksanaan proses pembelajaran khususnya mata pelajaran PJOK di SMA/Sederajat. Penelitian ini juga melibatkan jumlah sampel yang sangat banyak sehingga data yang dihasilkan bisa dinyatakan valid. Keunggulan lainnya dari penelitian ini terdapat pada lokasi 
Amrizal Fadila, Didik Rilastiyo Budi, Arfin Deri Listiandi, Ngadiman \& Rifqi Festiawan | Evaluasi Pembelajaran Pendidikan Jasmani Berbasis Kurikulum 2013 di Sekolah Menengah Atas

penelitian yang sudah mewakili wilayah di Kabupaten Banyumas sehingga tidak ada konsentrasi data yang dominan pada suatu wilayah.

\section{SIMPULAN}

Berdasarkan hasil penelitian yang telah dilaksanakan, dianalisa dan dilakukan pembahasan, maka dapat disimpulkan bahwa pelaksanaan pembelajaran PJOK Kurikulum 2013 di Kabupaten Banyumas khususnya pada SMA/Sederajat sudah terlaksana dengan baik, yang dilihat dari aspek guru dan siswa yang meliputi kompetensi inti, pelaksanaan proses pembelajaran dan pelaksanaan teknik penilaian. Pelaksanaan pembelajaran PJOK Kurikulum 13 yang telah baik di tingkat SMA perlu ditingkatkan dan dapat laksanakan oleh jenjang Pendidikan lain, baik SD, SMP maupun SMK.

\section{REFERENSI}

Agustan, B., Kusmaedi, N., Hendrayana, Y., Abduljabar, B., \& Ginanjar, A. (2020). Modifikasi pembelajaran: hybrid sport education-invasion games competence model terhadap performa permainan bola basket. Jurnal SPORTIF : Jurnal Penelitian Pembelajaran, 6(1), 157-172. https://doi.org/10.29407/js_unpgri.v6i1.14005

Budi, D. R., Hidayat, R., \& Febriani, A. R. (2019). The Application of Tactical Approaches in Learning Handballs. JUARA : Jurnal Olahraga. https://doi.org/10.33222/juara.v4i2.534

Budi, D. R., \& Listiandi, A. D. (2021). Model Pembelajaran Dalam Pendidikan Jasmani. https://doi.org/https://doi.org/10.31219/osf.io/xzh3g

Dewi, R. P., \& Sepriadi, S. (2021). Minat Siswa SMP Terhadap Pembelajaran PJOK Secara Daring Pada Masa New Normal. Physical Activity Journal, 2(2), 205. https://doi.org/10.20884/1.paju.2021.2.2.3988

Karisman, V. A. (2020). Implementasi Model Pembelajaran Terhadap Peningkatan Keterampilan Bermain Bola Voli. Physical Activity Journal, 2(1), 80. https://doi.org/10.20884/1.paju.2020.2.1.3096

Kemendikbud. (2013). Permendikbud Nomor 65 Tahun 2013 Tentang Standar Proses Pendidikan Dasar dan Menengah, Kementerian Pendidikan dan Kebudayaan Republik Indonesia. Jakarta.

Khudhori, M. (2015). Implementasi kurikulum 2013 pada mata pelajaran pendidikan jasmani, olahraga, dan kesehatan (PJOK) di SMA Negeri se-Kabupaten Jombang. Jurnal Pendidikan Olahraga Dan Kesehatan, 3(1), 211-214.

Kirom, A. (2017). Peran guru dan peserta didik dalam proses pembelajaran berbasis multikultural, . Jurnal Pendidikan Agama Islam, 3(1), 69-80. 
Kusuma, A. R. F. (2015). Implementasi kurikulum 2013 pada mata pelajaran pendidikan jasmani, olahraga, dan kesehatan di SMA Negeri se Kabupaten Situbondo,. Jurnal Pendidikan Olahraga Dan Kesehatan, 3(2), 501-505.

Mulyasa. (2017). Pengembangan dan implementasi kurikulum 2013. Bandung: PT Remaja Rosdakarya.

Nur, L., Malik, A. A., Juditya, S., Kastrena, E., Widyawan, D., Agustan, B., ... Yang, C. B. (2020). Comparison of two types of instruction in physical education. International Journal of Psychosocial Rehabilitation, 24(10), 1785-1793. https://doi.org/10.37200/IJPR/V24I10/PR300205

Pangaribuan, G. P., \& Aufan, R. (2020). Survey Penerapan Kurikulum 2013 Pada Mata Pelajaran Penjas Di Sekolah Menengah Pertama Negeri. Indonesian Journal of Sport Science and Coaching, 2(1), 35-45. https://doi.org/10.22437/ijssc.v2i1.9805

Rojali, W. I., Ngadiman, Budi, D. R., Nurcahyo, P. J., \& Febriani, A. R. (2021). Evaluasi Pembelajaran Daring Mata Pelajaran Pendidikan Jasmani Olahraga dan Kesehatan SMA Pada Era Pandemi Covid-19. Jurnal MensSana, 6(1), 92-99.

Rokim, M., \& Nurhayati, F. (2016). Survei keterlaksanaan kurikulum 2013 pada guru PJOK di SMA Negeri se Kabupaten Nganjuk. Jurnal Pendidikan Olahraga Dan Kesehatan, $4(1), 17-24$.

Sugiyono, P. D. (2016). metode penelitian kuantitatif, kualitatif,dan R\&D. In Alfabeta, cV. Bandung: Alfabeta. 